\title{
Expanding risk consideration in
} integrated models - the role of downside risk aversion in irrigation decisions

Journal Article

Author(s):

Finger, Robert (1)

Publication date:

2013-05

Permanent link:

https://doi.org/10.3929/ethz-b-000108794

Rights / license:

In Copyright - Non-Commercial Use Permitted

Originally published in:

Environmental Modelling \& Software 43, https://doi.org/10.1016/j.envsoft.2013.02.001 


\section{Postprint}

This is the accepted version of a paper published in Environmental Modelling \& Software. This paper has been peer-reviewed but does not include the final publisher proof-corrections or journal pagination.

\section{Citation for the original published paper:}

Finger, R. (2013). Expanding risk consideration in integrated models - the role of downside risk aversion in irrigation decisions. Environmental Modelling \& Software 43: 169-172. https://doi.org/10.1016/j.envsoft.2013.02.001

Access to the published version may require subscription.

N.B. When citing this work, cite the original published paper. 


\title{
Expanding risk consideration in integrated models
}

\section{- the role of downside risk aversion in irrigation decisions}

\begin{abstract}
We present a bio-economic model that accounts for the effects of water and nitrogen use on the first three moments of profit margin distributions in Swiss maize production. We thus also account for downside risks in farmers' decision making processes, which extents currently used bio-economic modeling approaches that address agricultural water use. We find that because irrigation reduces the skewness of profit margin distributions, i.e. downside risk, farmers have an additional incentive to use irrigation more intensively. Not considering downside risks may thus imply an underestimation of agricultural water use.
\end{abstract}

Keywords: Irrigation, risks, risk aversion, downside risks

\section{$1 \quad$ Introduction}

Currently employed integrated modeling approaches addressing environmental problems arising from agricultural land- and input use decisions have acknowledged the importance of explicitly representing farmers' decision making processes. This incorporation often relies on the assumption of profit maximization (e.g. Ahrends et al., 2008; deVoil et al., 2006; Gömann et al., 2005). However, farmers do not only seek to maximize profits but also try to secure their incomes by minimizing risks (e.g. Dury et al., 2010). This is of particular relevance if agricultural water use is addressed because irrigation has a risk reducing effect. By decoupling revenues from volatile rainfall patterns, irrigation can lead to substantial reductions of profit variability. Based on this background, many models focusing on agricultural water use have been extended by integrating farmers' preferences against more volatile profits by accounting for risk aversion (Bazzani et al. 2005; Bergez et al., 2012; Monticino et al., 2007) ${ }^{1}$. However, besides reducing volatilities of yields and profits, irrigation furthermore also reduces the probability that exceptional low yields or profits occur (e.g. due to crop

\footnotetext{
${ }^{1}$ See also Howitt et al. (2012), Marinoni et al. (2011) and Peña-Haro et al. (2011) for analyses focusing on decision making in the context of irrigated agriculture
} 
failure), i.e. irrigation reduces downside risk. If farmers are down-side risk averse and try to avoid possibilities of falling below certain income thresholds, this property can give an additional incentive to use irrigation (e.g. Moschini and Hennessy, 2000). While downside risk aversion is integrated in several economic studies that show its relevance for decision making processes of farmers (e.g. Koundouri et al., 2006; Torkamani and Shajari, 2008; Groom et al., 2008), to our knowledge, no attempts have been made to augment integrated bio-economic models addressing agricultural water use by accounting for farmers' downside risk aversion. This article contributes filling this gap by presenting a straightforward integration of downside risk and downside risk aversion in a bioeconomic model. The relevance of this extension for the conclusions drawn is illustrated using an example of optimal nitrogen and irrigation use in Swiss maize production.

\section{$2 \quad$ Material and Methods}

\subsection{Estimating moments of profit margin distributions}

Our bio-economic modeling approach is based on simulation experiments from 6 sites derived with a crop model, which report maize yields for different combinations of input (nitrogen and irrigation water) use. In a first step, these observations are transformed into profit margins $\pi$, which are calculated as revenue (yield times crop price P) plus direct payments (DP), minus fixed (FC) and variable costs (VC), which consist of costs for nitrogen, irrigation water as well as cleaning and drying costs.

$$
E(\pi)=Y(N, W) P+D P-F C-V C
$$

Table 1 presents the here employed assumptions on costs and benefits in Swiss maize production.

Table 1. Costs and benefits in Swiss maize production.

\section{Revenue}

Maize price

Direct Payment

Fixed costs (for seeds, plant protection, machinery, irrigation equipment etc.)

Variable costs

Fertilizer

Water

Cleaning and drying
$365 \mathrm{CHF} / \mathrm{t}$

$1660 \mathrm{CHF} / \mathrm{ha}$

$2038 \mathrm{CHF} / \mathrm{ha}$

Sources: AGRIDEA and FiBL (2009); Torriani et al. (2007a); Spörri (2011), see Finger (2012) for details. 
To estimate the relationship between profit margin distribution moments and irrigation nitrogen application, we use a moment-based approach, allowing for flexible representation of production risks (Antle 1983, 1987). Choosing this method instead other approaches (e.g. Just and Pope, 1978), allows us to extent earlier bio-economic modeling approaches (e.g. Finger et al., 2011, Finger, 2012) by additionally investigating the effects of input use on yield skewness, which represents downside risks. In a first step, we estimate the expected (i.e. the mean) effect of nitrogen use and irrigation on profit margin. With respect to the functional form used at this step, we follow Finger and Hediger (2008) and employ a square root specification. Furthermore, we account for site-specific characteristics in all subsequently presented estimation steps by integrating fixed effects.

$$
\pi(N, W)_{i, j}=\alpha_{0}+\alpha_{j}+\alpha_{1} N^{0.5}+\alpha_{2} N+\alpha_{3} W^{0.5}+\alpha_{4} W+\alpha_{5}(N W)^{0.5}+\varepsilon
$$

$\pi(N, W)_{i, j}$ is the profit margin for year $\mathrm{i}$ at location $\mathrm{j}, \mathrm{N}$ and $\mathrm{W}$ denote the amounts of nitrogen and irrigation water, $\alpha_{0}$ is a general model intercept, $\alpha_{j}$ are site specific intercepts (that sum up to zero), and $\varepsilon$ is an error term. In a second step, the effects of input use on profit margin variance are estimated using the square root of $W$ and $N$ as explanatory variables (following Finger and Schmid, 2008), with $\varphi$ being the error term:

$$
E\left[\left(E\left(\pi(N, W)_{i, j}\right)-\pi(N, W)_{i, j}\right)^{2}\right]=\beta_{0}+\beta_{j}+\beta_{1} N^{0.5}+\beta_{2} W^{0.5}+\varphi
$$

Finally, the effects of input use on the skewness of profit margins are estimated as follows (with error term $\vartheta)$

$$
E\left[\left(E\left(\pi(N, W)_{i, j}\right)-\pi(N, W)_{i, j}\right)^{3}\right]=\gamma_{0}+\gamma_{j}+\gamma_{1} N^{0.5}+\gamma_{2} W^{0.5}+\vartheta
$$

The employed estimation strategy for this moment based approach follows, for instance, Di Falco and Chavas $(2006,2009)$. The estimation results critically depend on the functional forms used in (2)-(4). We used different specifications, and compared models using Wald tests, leading to the here presented models. The detailed presentations of the results derived for other functional forms are beyond the scope of this paper, but can be obtained from the authors upon request. 


\subsection{Integrating risk in economic model components}

Farmers may benefit from irrigation in three ways. First, irrigation increases yield levels and thus also profit margins up to a certain point. Second, irrigation is expected to decrease yield variance, and third, to increase skewness (i.e. reduces downside risk). This means, risks decrease with increasing irrigation intensity. Note that the latter property is not captured by the variance, because this measure does not distinguish between unexpected bad and unexpected good events (Di Falco and Chavas, 2009). In contrast to irrigation, nitrogen is expected to be risk increasing (e.g. Finger et al., 2011, Finger, 2012). To quantify the farmers' benefits from all three effects in monetary terms, certainty equivalents are used. The certainty equivalent represents a sure amount of money that is rated by the farmer similar (i.e. he is indifferent) as volatile profit margins from (risky) crop production. In the certainty equivalent (CE) framework, the utility loss due to risk (i.e. due to variance and skewness of profit margins) is defined as the risk premium RP, which is subtracted from the expected profit margin.

$$
C E=E(\pi)-R P
$$

Following Di Falco and Chavas (2006), we define the (approximate) risk premium in our analysis as follows:

$$
R P=\frac{1}{2} r_{2} \sigma_{\pi}^{2}+\frac{1}{6} r_{3} \sigma_{\pi}^{3}
$$

$\sigma_{\pi}^{2}$ and $\sigma_{\pi}^{3}$ are the variance and skewness of profit margins that are taken from equations 3 and $4 . r_{2}$ and $r_{3}$ characterize the decision maker's aversion against variance and (negative) skewness. We base our analysis on a power utility function $U=\frac{1}{1-\tau} \pi^{1-\tau}$. With $r_{2}$ and $r_{3}$ being defined as -U', $/ \mathrm{U}$, and U','U', respectively (e.g. Chavas et al, 2009; Di Falco and Chavas, 2006, 2009), this choice implies $r_{2}=\tau / \pi$ and $r_{3}=-\left(\tau^{2}+\tau\right) / \pi^{2}$. Thus, we assume constant relative risk aversion, i.e. absolute risk aversion increases if expected profit margins approach zero. Important for the purpose of our paper, the latter term shows that a more negative skewness of profit margins increases the risk premium, i.e. the costs of risk. 
This framework is now used to derive optimal, i.e. certainty equivalent maximizing, levels of nitrogen use and irrigation. Thus, the goal function of our model is $\max _{W, N} C E$. To investigate the role of risk aversion in general and the role of downside risk aversion in particular, we investigate optimal input use for 4 different scenarios with $\tau$ being $0,1,2$ and 3. $r_{2}$ is thus equal to $0,1 / \pi, 2 / \pi$ and $3 / \pi$, and $r_{3}$ is equal to $0,-2 / \pi^{2},-6 / \pi^{2}$ and $-12 / \pi^{2}$, respectively. Furthermore, we conduct for the latter 3 scenarios an analysis with and without consideration of $r_{3}$ to investigate the role of downside risks. The employed scenarios represent a gradient from zero to moderate (downside) risk aversion (see e.g. Groom et al, 2003; Di Falco and Chavas, 2006, 2009).

\subsection{Data}

We use quasi-experimental data derived for maize production at the Swiss Plateau simulated with deterministic crop yield simulation model CropSyst, derived from Finger et al. (2011) and Finger (2012). In CropSyst, above- and below-ground processes such as the soil water budget, soil-plant nitrogen budget, crop phenology, canopy and root growth, and crop yield are simulated in response to crop and soil characteristics, daily weather data, and management options (see Stöckle et al., 2003, for details). Because these processes are affected, for instance, by water stress and nutrient deficits, effects of crop management regarding fertilizer application and irrigation on crop yields can be reflected. CropSyst settings for Swiss maize production follow Torriani et al. (2007b).

Effects of nitrogen application and irrigation intensity are analyzed with CropSyst in a quasiexperimental approach. To this end, different sets of daily weather data, i.e. representative outcomes of current climate at the Swiss Plateau for the years 1981-2003 from 6 meteorological stations are used. The weather years from these stations are combined with randomly drawn amounts of fertilizer and irrigation water. To simulate different irrigation intensities and thus different levels of water use, the intervention point is varied randomly. Irrigation is triggered when soil moisture falls below this intervention point. Irrigation can be used to fill up soil moisture to the field capacity level, but a single irrigation event is limited to $20 \mathrm{~mm}$. To mimic the water use efficiency of a sprinkler irrigation system, we assume that $25 \%$ of the applied water is not usable for the plant. The assumed soil texture 
is characterized with $38 \%$ clay, $36 \%$ silt, and $26 \%$ sand, and identical starting conditions regarding soil composition and soil available nutrients are used for each simulation. These simulations lead to 912 observations (see Finger et al., 2011; Finger, 2012, for details on data generation and descriptive summaries).

\section{$3 \quad$ Results and Discussion}

Table 2 shows coefficient estimates for equations 2-4, i.e. for the first three moments of the profit margin distribution. Results for the expected profit margin show that both inputs increase profit margins, however with a saturating effect. Without accounting for risks, applying inputs until their marginal effect on profit margins will be zero will lead to optimal levels of input use. We furthermore find that nitrogen increases the variance of profit margins and decreases its skewness, i.e. increases downside risk. In contrast, irrigation is found to reduce both the variance and the downside risk of profit margins. The coefficient estimates presented in Table 3 are input for the calculation of certainty equivalents (eq. 5), which are maximized with respect to nitrogen and water use.

Table 2. Coefficient Estimates.

\begin{tabular}{lccc}
\hline Variable & Expected profit margins & Variance of profit margins & Skewness of profit margins \\
Intercept & $1314.3420^{* * *}$ & $38547.53^{* * *}$ & $-11386344^{* * *}$ \\
$N^{0.5}$ & $77.0938^{* * *}$ & $5758.55^{* * *}$ & $-1658301^{* * *}$ \\
$N$ & $-4.4908^{* * *}$ & --- & --- \\
$W^{0.5}$ & $12.6905^{* * *}$ & $-2836.85^{* * *}$ & $1332486^{* *}$ \\
$W$ & $-0.9272^{* * *}$ & --- & --- \\
$(N W)^{0.5}$ & $0.6083^{* * *}$ & --- & --- \\
Pseudo $\mathrm{R}^{2}$ & 0.41 & 0.50 & 0.09 \\
\hline
\end{tabular}

$*, * *$ and $* * *$ denote significance at the $1 \%, 5 \%$ and $1 \%$ level, respectively.

Table 3 shows optimal, i.e. certainty equivalent maximizing, levels of input use for the different scenarios on risk aversion. Furthermore, the resulting optimal profit margins as well as their standard deviation and (standardized) skewness are presented. The optimal levels of nitrogen use and profit margins indicated by our model are in the range of current practices in Swiss agriculture (AGRIDEA and FiBL, 2009). Furthermore, standard deviations of profit margins are similar to observations for 
Swiss maize producers made by El Benni and Finger (2012). For irrigation levels and the skewness of profit margins, however, no reference values for comparisons are available.

Table 3. Optimization results.

\begin{tabular}{|c|c|c|c|c|c|c|c|}
\hline $\begin{array}{l}\text { Specification } \\
\text { of the power } \\
\text { utility function }\end{array}$ & $\mathbf{N}$ & $\mathbf{W}$ & $\begin{array}{l}\text { Expecte } \\
\text { d profit } \\
\text { margin }\end{array}$ & $\begin{array}{l}\text { Standard } \\
\text { deviation of } \\
\text { profit margin }\end{array}$ & $\begin{array}{l}\text { Standardized } \\
\text { skewness of } \\
\text { profit margin }\end{array}$ & $\begin{array}{l}\text { Certainty } \\
\text { Equivalents }\end{array}$ & $\begin{array}{l}\text { Risk } \\
\text { Premium }\end{array}$ \\
\hline $\begin{array}{l}\tau=0 \text { (risk } \\
\text { neutral) }\end{array}$ & 86 & 98 & 1733.68 & 252.72 & -0.84 & --- & --- \\
\hline $\begin{array}{l}\tau=1 \text {, without } \\
\text { downside risk } \\
\text { aversion }\end{array}$ & 83 & 105 & 1733.43 & 248.88 & -0.83 & 1715.57 & 17.87 \\
\hline $\begin{array}{l}\tau=1 \text {, with } \\
\text { downside risk } \\
\text { aversion }\end{array}$ & 82 & 107 & 1733.25 & 247.69 & -0.83 & 1714.15 & 19.10 \\
\hline $\begin{array}{l}\tau=2 \text {, without } \\
\text { downside risk } \\
\text { aversion }\end{array}$ & 80 & 113 & 1732.59 & 244.74 & -0.82 & 1698.02 & 34.57 \\
\hline $\begin{array}{l}\tau=2 \text {, with } \\
\text { downside risk } \\
\text { aversion }\end{array}$ & 79 & 118 & 1731.97 & 242.72 & -0.81 & 1694.07 & 37.90 \\
\hline $\begin{array}{l}\tau=3 \text {, without } \\
\text { downside risk } \\
\text { aversion }\end{array}$ & 77 & 121 & 1731.17 & 240.57 & -0.81 & 1681.02 & 50.15 \\
\hline $\begin{array}{l}\tau=3 \text {, with } \\
\text { downside risk } \\
\text { aversion }\end{array}$ & 76 & 131 & 1729.61 & 237.23 & -0.79 & 1673.72 & 55.89 \\
\hline
\end{tabular}

Comparing optimal input use under increasing levels of risk aversion (i.e. for higher levels of $\tau$ ) reveals the expected effects: More risk averse farmers use less nitrogen because it is risk increasing, but extent their risk reducing irrigation activities (i.e. increase water use). Underlining findings from earlier research (e.g. Finger, 2012), expected levels of input use may differ substantially depending on the assumed risk aversion. We find optimal nitrogen use to decrease from 86 to $76 \mathrm{~kg} / \mathrm{ha}$ and optimal water use to increase from 98 to $131 \mathrm{~mm}$, if comparing results for risk neutrality $(\tau=0)$ and moderate risk aversion with $\tau=3$. These changes in optimal production plans also imply lower standard deviations of profit margins and higher levels of skewness. In our numerical example, reducing risks comes at low costs, because decreases in expected profit margins are very small. This, however, should not marginalize the role of risk aversion, because its effects on input use can be still large.

Comparing optimal input use with and without consideration of downside risk aversion shows ambiguous results. We find only small impacts of downside risk aversion on optimal nitrogen use (of 
about $1 \mathrm{~kg} / \mathrm{ha}$ ). In contrast, the identified differences in optimal amounts of water use for irrigation can be substantial. The effect of downside risk aversion is stronger with respect to optimal use of irrigation because it has, in contrast to nitrogen use, a straightforward implication on the tails of crop yield and profit margin distributions. For the highest level of risk aversion $(\tau=3)$, taking downside risk aversion into account increases the optimal water use by $10 \mathrm{~mm}$ (or $8 \%$ ). This means, expected levels of water use for irrigation may be substantially underestimated in bio-economic models if its downside risk reducing effect is not considered.

We are aware that the numerical results with regard to the relevance of downside risk in optimal input use are limited to the here presented case study. For instance, integrating downside risk aversion in bio-economic models with a different scope (e.g. at the farm-level), accounting for different management options that influence water use (e.g. adjustments in the timing of field operations or tillage intensities) or accounting for different irrigation technologies (e.g. drip irrigation), will cause changes in the relevance of downside risks. However, we expect that accounting for downside risk aversion in other bio-economic modeling frameworks will also result in an increased relevance of irrigation as risk reducing strategy taken by the farmer. Reviewers suggested that the consideration of the Kurtosis of profit margin distribution and farmers preferences with respect to it should be considered in future research because it can allow a better representation of extreme events.

\section{Conclusion}

Irrigation does not only influence mean and variance of crop yields, but also increase crop yield skewness, i.e. decreases downside risks. Accounting for farmers' downside risk aversion may thus result in substantially different conclusions on agricultural water use. We present a straight-forward extension of a bio-economic model to include downside risks and downside risk aversion in bioeconomic models. This may be a valuable extension of currently used models also beyond irrigation decisions, because many agricultural inputs with high environmental relevance (e.g. pesticides) affect downside risks.

\section{References}


AGRIDEA, FiBL, 2009. Deckungsbeiträge, 2009. Swiss Association for the Development of Rural Areas (AGRIDEA) and Research Institute for Organic Agriculture (FiBL), Switzerland.

Ahrends, H., Mast, M., Rodgers, C., Kunstmann, H., 2008. Coupled hydrological economic modelling for optimised irrigated cultivation in a semi-arid catchment of West Africa. Environ. Modell. Softw. 23, 385-395.

Antle, J.M., 1983. Testing the Stochastic Structure of Production: A Flexible Moment-Based Approach. J. Busin. Econ. Stat. 1,192-201.

Antle, J., 1987. Econometric estimation of producers' risk attitudes. Am. J. Agric. Econ. 69, 509-522.

Bazzani, G.M., Di Pasquale, S., Gallerani, V., Morganti, S., Raggi, M., Viaggi, D., 2005. The sustainability of irrigated agricultural systems under the Water Framework Directive: first results, Environ. Modell. Softw. 20, 165-175.

Bergez, J.-E., Chabrier, P., Gary, C., Jeuffroy, M.H., Makowski, D., Quesnel, G., Ramat, E., Raynal, H., Rousse, N., Wallach, D., Debaeke, P., Durand, P., Duru, M., Dury, J., Faverdin, P., GascuelOdoux, C., Garcia, F., 2012. An open platform to build, evaluate and simulate integrated models of farming and agro-ecosystems. Environ. Modell. Softw., in press.

Chavas, J.P., Posner, J.L., Hedtcke, J.L., 2009. Organic and Conventional Production Systems in the Wisconsin Integrated Cropping Systems Trial: II. Economic and Risk Analysis 1993-2006. Agron. J. 101, 288-295.

deVoil, P., Rossing, W.A.H., Hammer, G.L., 2006. Exploring profit-sustainability trade-offs in cropping systems using evolutionary algorithms. Environ. Modell. Softw. 2, 1368-1374.

Di Falco, S., Chavas, J.-P., 2006. Crop Genetic Diversity, Farm Productivity and the Management of Environmental Risk in Rainfed Agriculture. Europ. Rev. Agric. Econ. 33, 289-314.

Di Falco, S., Chavas, J.-P., 2009. On Crop Biodiversity, Risk Exposure and Food Security in the Highlands of Ethiopia. Am. J. Agric. Econ. 91, 599-611.

Dury, J., Garcia, F., Reynaud, A., Therond, O., Bergez, J.E., 2010. Modelling the Complexity of the Cropping Plan Decision-making", IEMS, Ottawa, Canada.

El Benni, N., Finger, R., 2012. Where Is the Risk? Price, Yield and Cost Risk in Swiss Crop Production. 28th Triennial Conference of the International Association of Agricultural Economists (IAAE), August 18 to 24, 2012, Foz do Iguaçu, Brazil.

Finger, R., Hediger, W., 2008. The Application of Robust Regression to a Production Function Comparison. Open Agric. J. 2, 90-98

Finger, R., Schmid, S., 2008. Modeling Agricultural Production Risk and the Adaptation to Climate Change. Agr. Finance Rev. 68, 25-41

Finger, R., Hediger, W., Schmid, S., 2011. Irrigation as Adaptation Strategy to Climate Change: A Biophysical and Economic Appraisal for Swiss Maize Production. Climatic Change 105, 509-528.

Finger, R., 2012. Modeling the sensitivity of agricultural water use to price variability and climate change - an application to Swiss maize production. Agr. Water Manage. 109, 135-143.

Gömann, H., Kreins, P., Kunkel, R., Wendland, F., 2005. Model based impact analysis of policy options aiming at reducing diffuse pollution by agriculture - a case study for the river Ems and a sub-catchment of the Rhine. Environ. Modell. Softw., 20, 261-271.

Groom, B., Koundouri, P., Nauges, C., Thomas, A., 2008. The story of the moment: risk averse cypriot farmers respond to drought management. Applied Economics 40, 315-326.

Howitt, R.E., Medellín-Azuara, J., MacEwan, D., Lund, J.R., 2012. Calibrating disaggregate economic models of agricultural production and water management. Environ. Modell. Softw., 38, 244-258.

Just, R.E., Pope, R.D., 1978. Stochastic Specification of Production Functions and Economic Implications. J. Econometrics 7, 67-86.

Koundouri, P., Nauges, C., Tzouvelekas, V., 2006. Technology adoption under production uncertainty: theory and application to irrigation technology. Am. J. Agric. Econ. 88, 657-670. 
Marinoni, O., Adkins, P., Hajkowicz., S., 2011. Water planning in a changing climate: Joint application of cost utility analysis and modern portfolio theory Environmental Environ. Modell. Softw., 26, 18-29.

Monticino, M., Acevedo, M., Callicott, B., Cogdill, T., Lindquist, C., 2007. Coupled human and natural systems: A multi-agent-based approach. Environ. Modell. Softw. 22, 656-663.

Moschini, G., Hennessy, D.A., 2000. Uncertainty, Risk Aversion and Risk Management for Agricultural Producers, in: Gardner, B., Rausser, G. (eds.), Handbook of Agricultural Economics, Amsterdam, Elsevier Science Publishers, pp. 88-153.

Peña-Haro, S., Pulido-Velazquez, M., Llopis-Albert, C., 2011. Stochastic hydro-economic modeling for optimal management of agricultural groundwater nitrate pollution under hydraulic conductivity uncertainty. Environ. Modell. Softw.,26, 999-1008.

Spörri, M., 2011. Economic Efficiency of Irrigation Strategies for arable crops under current and future climate scenarios. Bachelor Thesis, ETH Zurich, Switzerland.

Stöckle, C.O., Donatelli, M. Nelson, R., 2003. CropSyst, a cropping systems simulation model. Eur. J. Agron. 18, 289-307.

Torkamani, J., Shajari, S., 2008. Adoption of new irrigation technology under production risk. Water Resour. Mana. 2, 229-237.

Torriani, D.S., Calanca, P., Lips, M., Ammann, H., Beniston, M., Fuhrer, J., 2007a. Regional assessment of climate change impacts on maize productivity and associated production risk in Switzerland. Reg. Environ. Change 7, 209-221.

Torriani, D.S., Calanca, P., Schmid, S., Beniston, M., Fuhrer, J., 2007b. Potential effects of changes in mean climate and climate variability on the yield of winter and spring crops in Switzerland. Clim. Res. 34, 59-69. 